\title{
OS PRINCIPAIS PASSOS ADOTADOS NA APLICAÇÃO DE KAIZEN EM FABRICANTE DE COMPONENTES INDUSTRIAIS SERIADOS
}

\section{THE MAIN STEPS ADOPTED IN THE APPLICATION OF KAIZEN IN AN INDUSTRIAL SERIAL COMPONENTS MANUFACTURER}

\author{
Manoel Gonçales Filho* E-mail: mlgoncales@unimep.br \\ Sílvio Roberto Ignácio Pires* E-mail: sripires@unimep.br \\ *Universidade Metodista de Piracicaba (UNIMEP) - Piracicaba (SP)
}

\begin{abstract}
Resumo: A concorrência enfrentada pelo setor metal mecânico no Brasil faz com que as empresas busquem tornarem-se cada vez mais competitivas. Essa condição induz a melhorias contínuas, dentre elas o desenvolvimento dos sistemas produtivos. Assim, uma nova orientação estratégica operacional se faz necessária para atingir os objetivos de maximização dos lucros, e de sobressair-se à concorrência, por meio de uma maior produtividade. O objetivo deste artigo é relatar sobre os principais passos a serem realizados na busca da melhoria do processo produtivo, e mensurar ganhos quantitativos pela aplicação de kaizens nos setores que fabricam componentes metálicos para a indústria de equipamentos e máquinas de grande porte. Nesse sentido, este trabalho investiga o processo produtivo de um fabricante de componentes industriais operando na região de Piracicaba/SP. O método de pesquisa utilizado partiu de uma revisão bibliográfica na área da Engenharia de Produção, acerca da Produção Enxuta e da eliminação de desperdícios por meio de kaizens. Posteriormente, foi realizado um estudo de caso de caráter exploratório na empresa pesquisada. Os resultados mostram que foi possível eliminar desperdícios e promover melhorias no processo de fabricação, reduzir a superprodução, o tempo de espera, a movimentação e transporte excessivo de peças e componentes, e obter-se ganhos de espaço na fábrica e redução da mão de obra diretamente empregada no processo produtivo.
\end{abstract}

Palavras-chave: Produção Enxuta. Kaizen. Sistema Produção Empurrado e Puxado. Processo Produtivo.

\begin{abstract}
The competition faced by the metal-mechanical sector in Brazil impels companies to pursue competitiveness. This condition induces continuous improvements, among them the development of productive systems. Thus, a new operational strategic orientation is necessary to achieve the goals of maximizing profits, and to stand out from the competition, through greater productivity. The objective of this article is to report on the main steps to be taken in the pursuit of improvement of the productive process, and to measure quantitative gains by the application of kaizen in the sectors that manufacture metallic components for the large equipment and machinery industry. In this sense, this work investigates the production process of a manufacturer of industrial components operating in the region of Piracicaba / SP. The research method used was based on a literature review in the field of Production Engineering, about Lean Production and the elimination of waste by kaizen. Subsequently, a case study of an exploratory nature was carried out in the company investigated. The results show that it was possible to eliminate waste and promote improvements in the manufacturing process, reduce overproduction, waiting time, excessive movement and transportation of parts and components, and gains in factory space and labor shortages directly employed in the production process.
\end{abstract}

Keywords: Lean Production. Kaizen. Pulled and Pulled Production System. Productive Process. 


\section{INTRODUÇÃO}

A concorrência global tem impulsionado as empresas industriais a se tornarem mais competitivas e essa condição tem as induzidas a uma incessante busca por melhorias contínuas, dentre elas o desenvolvimento dos sistemas produtivos.

Devido às mudanças necessárias para promover essas melhorias, existe a necessidade de as organizações adotarem uma nova postura perante seus processos internos, clientes, concorrentes e fornecedores, com nova orientação estratégica para atingir os objetivos da organização, tornando-as mais competitiva (THOMAS, 2012). Dües et al. (2013) confirmaram essa condição em suas pesquisas, demonstrando que, inicialmente, a utilização do Kaizen dentro da estrutura do escopo da Produção Enxuta se reverte em benefícios operacionais, sendo ampliados para benefícios financeiros e competitivos.

Favoni et al. (2013) relatam que a Produção Enxuta se baseia em esforços para a eliminação de desperdícios e em atividades que não agregam valor ao consumidor e que possam ser otimizados ou eliminados por meio da aplicação de conceitos e ferramentas, e que assim se pode enfrentar o desafio da melhoria da competitividade e à sobrevivência no mercado. Os autores mencionam que esses desafios são comuns às todas as empresas como, por exemplo, a redução de desperdícios, necessidade de melhorias no fluxo de valor, além do pouco conhecimento sobre a Produção Enxuta e da implementação dessas ferramentas. Observaram ainda a oportunidade de aplicação de algumas poucas ferramentas que podem contribuir para melhorias nas empresas de vários segmentos de atuação.

O objetivo principal deste artigo está além da aplicação de ferramentas e técnicas da Produção Enxuta, pois busca-se apresentar, de forma ordenada e bem particular, alguns poucos e principais passos iniciais seguidos pela prática da indústria que poderão ser suficientes para uma efetiva melhoria do processo produtivo.

Assim, como uma sequência lógica, prática, objetiva e bem-sucedida de convergência, pôde-se mensurar ganhos quantitativos, e identificar as áreas desenvolvidas pela aplicação do Kaizen.

Nesse contexto, investigou-se as contribuições teóricas identificadas na revisão bibliográfica sob a ótica da Engenharia de Produção, mais especificamente 
da Produção Enxuta, face ao que foi desenvolvido na prática por uma indústria do segmento metal mecânico localizada no interior do estado de São Paulo. Para tal foi conduzido um estudo de caso na empresa PiraMetals (nome hipotético), na região de Piracicaba, reconhecida pelo mercado local como líder na fabricação de peças seriadas sob a especificação dos clientes.

\section{PRODUÇÃO ENXUTA E KAIZEN}

A seguir será apresentado uma breve revisão acerca dos conceitos da Produção Enxuta e Kaizen.

\subsection{Origem e filosofia}

O Sistema Toyota de Produção (STP) surgiu de um estudo realizado por Eiji Toyoda e seu engenheiro de produção Taiichi Ohno, baseado em um modelo já existente aplicado na fábrica da Ford (LIKER, 2004). O sistema de produção da Ford era um sistema "empurrado" considerado como sendo a produção controlada por uma central de planejamento que considera previsões de futuras demandas (GSTETTNER e KUHN, 1996; SPEARMAN, WOODRUFF, HOPP, CONWIP, 1990). Por sua vez o STP era um sistema "puxado" sendo considerado como aquele que autoriza a produção de determinado item por meio da demanda presente ao invés de programar a produção, antecipadamente, por meio de demanda futura (HOPP e SPEARMAN, 2013).

Segundo Ohno (1997), o STP está baseado em quatro elementos principais que são: filosofia, processo, pessoas/parceiros e solução de problemas, os quais estão representados na Figura 1, atrelados aos seus 14 princípios de funcionamento. 


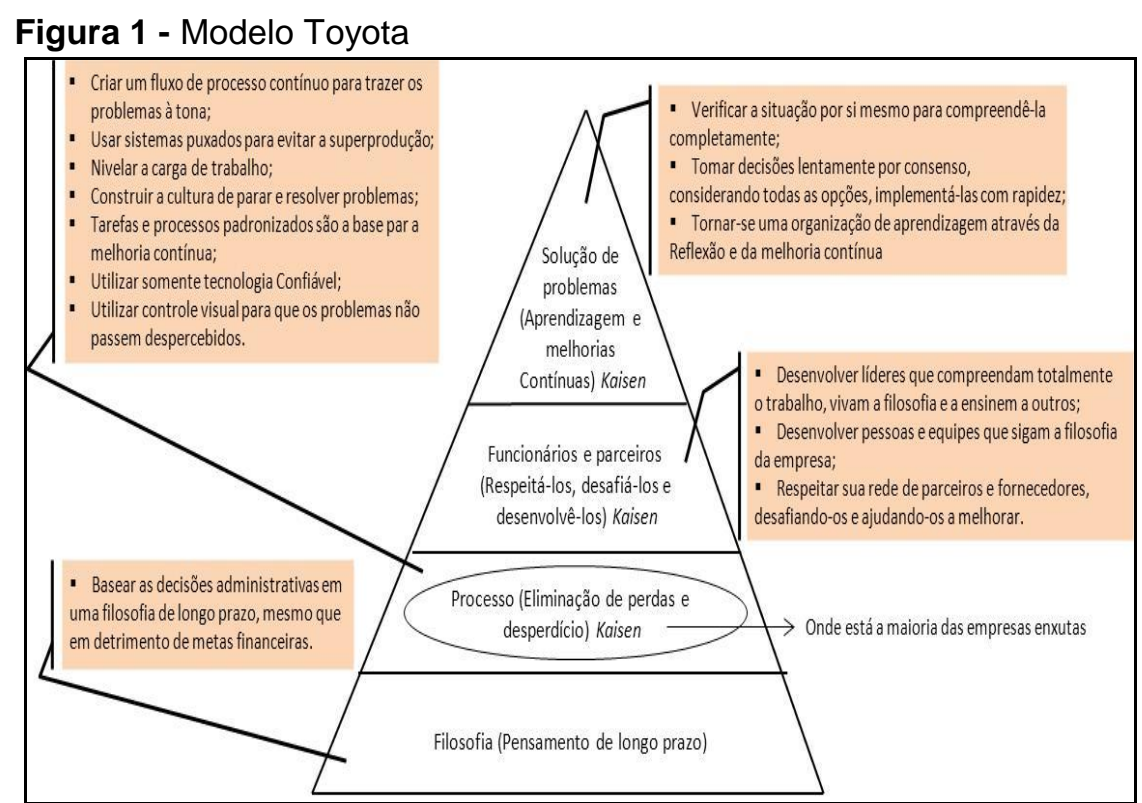

Fonte: Adaptado de Liker (2004).

Conforme Liker (2004) o ganho principal do STP não está apenas nas ferramentas e técnicas como Just in Time (JIT), Kanban, entre outras, que geram economicidade de recursos, mas sim no comprometimento administrativo de uma empresa por meio de um investimento permanente na capacitação do seu pessoal e a promoção de uma cultura de melhoria contínua, que no contexto do STP são denominados de Kaizen.

O Kaizen foi desenvolvido pelos criadores do STP com o objetivo reformular o modelo de administração clássica de Fayol, melhorando continuamente os processos e operações das empresas japonesas (SINGH; SINGH, 2009).

\subsection{Ferramentas enxutas}

Para a implementação de Kaizen's é necessário a aplicação de algumas ferramentas enxutas como o Mapeamento do Fluxo de Valor (VSM - Value Stream Map) que pode ser considerado um método para ilustrar os fluxos de valor (OHNO, 1997). Consiste em duas etapas principais: na $1^{\text {a }}$ etapa visualiza-se o fluxo de valor atual (estado atual) e realiza-se a análise do layout desse fluxo verificando onde existem fontes de desperdícios. $\mathrm{Na} 2^{\underline{a}}$ etapa esses desperdícios identificados são reduzidos e cria-se um novo fluxo de valor (estado futuro), atacando-se também prazos de entrega e redução dos inventários (ROTHER, 2003). 
Layout é o posicionamento no espaço de departamentos ou postos de trabalho, de modo a minimizar um custo, satisfazendo um conjunto de restrições. É importante destacar os tipos de layouts existentes: layouts fixos, layouts de processos intermitentes, layouts em linha e layouts de fluxo contínuo (SEELING e PANITZ, 1997). No presente estudo serão tratados apenas layouts de fluxo contínuos.

São considerados sistemas de fluxo em linha ou contínuos, um sistema produtivo onde o layout possui uma alta eficiência e inflexibilidade intensa, geralmente produzindo por longos períodos de tempo, com alto volume e uma variedade baixa de produtos. Assim é considerado contínuo pelo fato do processo ser em um fluxo ininterrupto (OHNO, 1997).

Portanto, um sistema de produção contínua visa produzir uma maior quantidade no menor tempo possível, ou seja, uma produção constante sem paradas ou interrupções.

Uma das funções fundamentais do STP é a padronização que envolve e capacita todos os funcionários para melhorar o sistema como um todo. $O$ trabalho padronizado propõe uma maneira diferente de agir, motivando toda a organização para um trabalho mais eficiente, oferecendo uma qualidade superior a um menor custo (JOHANSSON et al. 2013).

Segundo Léxico Lean (2003) outra ferramenta que auxilia as empresas nesse processo é o 5S, o qual origina-se da primeira letra de cinco operações: Seiri (utilização), Seiton (arrumação), Seiso (limpeza), Seiketsu (normalizar) e Shitsuke (disciplina). O $5 \mathrm{~S}$ auxilia o desenvolvimento das equipes operacionais no gemba (chão de fábrica), alterando o modo de gestão e criando um padrão disciplinar entre todos. Tem como objetivo desenvolver um ambiente visual, onde o ambiente é limpo e bem organizado, com fluxos claramente identificados, informações e objetos facilmente disponíveis e padronizados visualmente (BERTHOLEY et al. 2009). O desenvolvimento desses novos hábitos e regras de trabalho reduzem significativamente as ineficiências e desperdício de tempo nas atividades diárias. Vale ressaltar que tal metodologia exige o esforço de todos os envolvidos com um propósito em comum, melhorar seu local de trabalho, simplificando as atividades diárias por meio de mudanças graduais focadas na obtenção de um ambiente mais agradável e eficiente (GAPP, FISHER, KOBAYASHI, 2008). 
O Kanban (sistema de controle da produção) é uma ferramenta que funciona entre estações de trabalho consecutivas. Sua principal função é regular os níveis de estoque, mantendo-os o mais baixo possível sem comprometer a produção. Quando o estoque intermediário da estação de trabalho seguinte está baixo, o Kanban permite que a produção se inicie na estação anterior (HOPP e SPEARMAN, 2013).

A manutenção contínua de um sistema de produção é fundamental, afinal não pode haver atrasos no processo. Uma ferramenta que auxilia essa manutenção é o TPM (Total Productive Maintenance) ou Manutenção Produtiva Total. O conceito de TPM é implementado por fases e começa com o 5S. Nakajima em 1988, foi o pioneiro a realizar um trabalho que deu a definição básica de TPM, sua importância, objetivos, vantagens e desvantagens, e passos a serem seguidos durante a implementação. Essa metodologia veio para atacar as enormes perdas e desperdícios que ocorriam no chão de fábrica, advindas de falhas ou mau treinamento dos operadores, pessoal de manutenção, processos, problemas de ferramentas e não disponibilidade de componentes em tempo. E que abrange ainda outros fatores como máquinas ociosas, mão de obra ociosa, quebra de máquina e rejeição de peças (SINGHA et al. 2013).

Conforme Kasahara e Carvalho (2003), as fases no que diz respeito ao aperfeiçoamento do processo e do treinamento das pessoas para que possam obter melhores resultados é denominado DMAIC.

O DMAIC, apresentado pela Figura 2, é um modelo estruturado, sistematizado e utilizado para orientar as fases de implementação de mudanças na produção.

Figura 2 - Fases do DMAIC

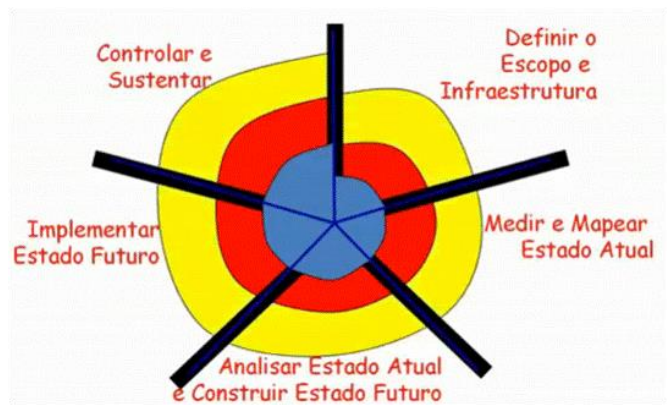

Fonte: Hominiss (2015) 
As fases são: definir o escopo, objetivos e a infraestrutura, medir e mapear o estado atual do processo produtivo, analisar o estado atual e futuro, implementar o estado futuro, e controlar o estado futuro. E começar tudo novamente, como um ciclo, o ciclo DMAIC.

Outra ferramenta que pode apoiar o STP é o Lean Six Sigma, que advém de uma metodologia que combina Lean com Six Sigma, o que o torna um processo dinâmico para o controle dos custos, processos, resíduos e fatores críticos para atender exigências dos clientes. É a combinação das duas metodologias para trabalhar na redução dos custos e desperdícios nas organizações (CELIS e GARCIA, 2012).

Todas essas ferramentas são passíveis de serem aplicadas conjuntamente com o a Kaizen, que tem sido amplamente mencionada ao produzir mudanças e resultados positivos para as empresas que as aplica (SUÁREZ-BARRAZA et al. 2011).

Mano et al. (2014) relata que especialistas em Kaizen sustentam que essa ferramenta ajuda a motivar os trabalhadores a prestarem atenção a aspectos da operação do negócio, de forma a melhorar a produtividade e a qualidade do produto. O objetivo do Kaizen é sempre estar em busca da melhoria contínua, a metodologia pode refletir diretamente junto à produtividade e à qualidade com o mínimo investimento. Para sua implementação as pessoas na organização desenvolvem suas atividades, melhorando-as sempre, por meio de reduções de custos e alternativas de mudanças inovadoras. O trabalho coletivo prevalece sobre 0 individual e o ser humano é visto como um dos bens mais valiosos da organização e deve ser estimulado a direcionar seu trabalho para as metas compartilhadas da empresa, atendendo suas necessidades humanas; satisfação e responsabilidade são valores coletivos (MANO et al. 2014).

Dessa forma, Imai (1986) descreve uma série de inovações da gestão japonesa: (i) gestão da qualidade total; (ii) just in time; (iii) kanban; (iv) zero defeito; (v) sistemas de sugestões; (vi) manutenção preventiva total; (vii) orientação para o consumidor; (viii) automação; (ix) disciplina no local de trabalho; $(\mathrm{x})$ atividades em pequenos grupos; (xi) relações cooperativas entre administração e mão de obra e; (xii) melhoria da produtividade e desenvolvimento de novos produtos. Para este autor, existem dez mandamentos que devem ser seguidos: 1 - O desperdício deve ser eliminado; 2 - Melhorias graduais devem ser feitas continuamente; 3 - Todos os Revista Produção Online. Florianópolis, SC, v.17, n. 4, p. 1160-1178, 2017. 
colaboradores devem ser envolvidos; 4 - Buscar aumento da produtividade com estratégias de baixo custo; 5 - Pode se aplicar o Kaizen em todas as áreas da organização; 6 - Fazer uso da gestão visual possibilitando visibilidade a problemas e os avanços das atividades, por meio de informações necessárias e visão macro a disposição de todos; 7 - Focaliza a ação onde existe maior criação de valor no chão de fábrica; 8 - Deve ser orientado para os processos; 9 - Valoriza o ser humano, possibilitando sua participação e crescimento no trabalho em equipe; 10 - O lema essencial da aprendizagem organizacional é: Aprender fazendo.

Igualmente, a título de corroborar com o tema, o Kaizen não será bemsucedido se os colaboradores não receberem um treinamento e apoio adequado (MARKSBERRY et al. 2010).

É vasta a literatura disponível sobre as ferramentas de aplicação que visam a melhoria dos processos. Encontra-se uma série de propostas e, supostamente, seus passos de implementação estão de forma ordenada, e poderiam ser utilizadas por organizações de diversos segmentos. A fundamentação teórica, obtida por meio da revisão bibliográfica, possibilitou a identificação desses elementos da Produção Enxuta que são passíveis de serem observados, analisados e comparados com a prática adotada pela empresa presente neste estudo de caso, e está exposto no Capítulo 4, na apresentação e análise dos resultados.

Favoni (2013), trabalhou com 12 ferramentas que contribuíram para melhorias em empresa do segmento industrial de calçados. São elas: 1. Produção Puxada e Fluxo Contínuo, 2. Integração da Cadeia de Fornecedores, 3. Operações Padronizadas, 4. Nivelamento da Produção, 5. Balanceamento da Produção, 6. Flexibilização da Mão de obra, 7. TQM, 8. TPM, 9. Troca Rápida de Ferramentas, 10. Gestão Visual, 11. Melhoria Contínua e, 12. Mapeamento do Fluxo de Valor (MFV).

Nogueira e Saurin (2008) propuseram uma avaliação do nível de implementação de típicas práticas da Produção Enxuta em uma empresa do setor metal-mecânico para melhoria dos processos produtivos, e consideraram 15 Etapas necessárias para de implementação. São elas: 1. Tecnologia de grupo, 2. Gerenciamento visual, 3. Manutenção produtiva total, 4. Desenvolvimento de produto enxuto, 5. Flexibilização da mão-de-obra, 6. Melhoria continua, 7. Balanceamento da produção, 8. Controle de qualidade zero defeitos, 9. Mapeamento do fluxo de valor, 10. Automação, 11. Troca rápida de ferramenta, 12. Nivelamento da produção, 13. Integração da cadeia de fornecedores, 14. Operações padronizadas e, 15. Just-inRevista Produção Online. Florianópolis, SC, v.17, n. 4, p. 1160-1178, 2017. 
time.

Scheller e Miguel (2014) notaram que, inicialmente, na empresa de manufatura de refrigeração doméstica, foco de sua pesquisa, não havia consenso em relação a sua estrutura organizacional e tampouco de implementação. $\mathrm{Na}$ ocasião da iniciativa de melhoria dos processos, teve como primeiro passo, um trabalho de sensibilização de toda a liderança. As práticas utilizadas totalizaram 19 Fases.

O trabalho de Oliveira et al. (2014) tem como objetivo promover melhorias no processo produtivo de modo integrado a um modelo de simulação computacional. $\mathrm{O}$ objeto de estudo está baseado em um sistema produtivo que envolve um processo de embalamento automático de produtos. Identificou-se dados do sistema atual e possibilidades de resultados futuros, e registrou-se as atividades que agregam valor ou não para o processo, para posterior aplicação de kaizen.

\section{METODOLOGIA}

Para se verificar in loco o que a literatura nacional e internacional disponibiliza na área da Engenharia de Produção, sobre a filosofia do Sistema Toyota de Produção (STP) e seus resultados, escolheu-se no Brasil, na região de Piracicaba, estado de São Paulo, uma empresa industrial com $12.000 \mathrm{~m}^{2}$ de área construída para análise de suas práticas.

A revisão bibliográfica, de natureza exploratória, contou com as seguintes etapas de triagem para compor o banco de documentos: (i) Identificação dos periódicos nacionais e internacionais disponíveis por meio das palavras chaves: Engenharia de Produção, Produção Enxuta, Kaizen, Sistema Produção Empurrado, Sistema Produção Puxado; (ii) Seleção das bases de dados a ser trabalhada; (iii) $O$ recurso utilizado e o foco dado ao tipo de documento aplicado, no caso apenas artigos; (iv) A temporalidade da produção dos artigos e, finalmente; (v) $O$ procedimento da leitura na identificação da contribuição (estado da arte) dos artigos de forma a embasar esta pesquisa. A Figura 3 apresenta o fluxo de organização da pesquisa teórica e dos artigos trabalhados. 
Figura 3 - Etapas de triagem para compor o referencial teórico

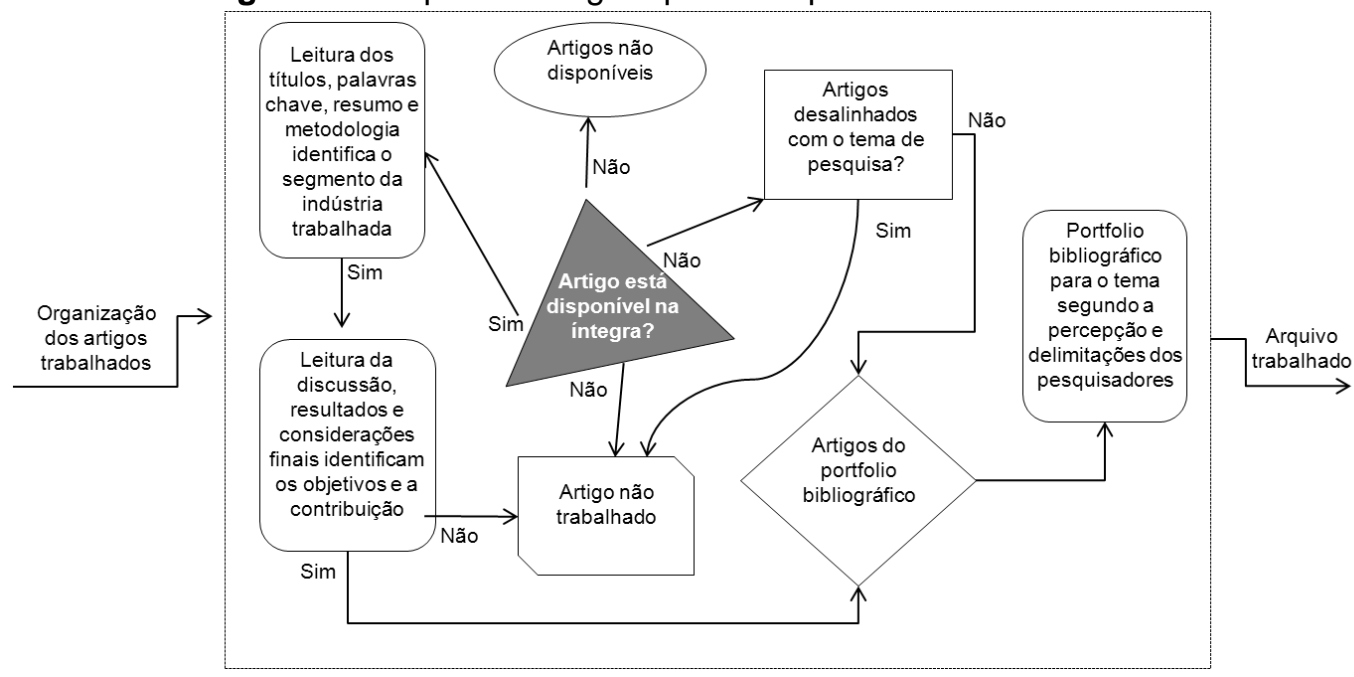

Para atingir o objetivo desta pesquisa, e após definido a estrutura conceitual teórica na revisão da literatura, partiu-se para o caso a ser estudado. Inicialmente, com o teste piloto anterior a aplicação do kaizen, (pré-kaizen - período de apontamentos das informações que antecede a execução da melhoria) e, posteriormente, aplicou-se a pesquisa por meio de questionário e da observação da execução prática do kaizen. Após a coleta e análise dos dados, gerou-se o relatório, conforme procedimento metodológico estruturado e relatado por Miguel (2007). Essa coleta dos dados ocorreu por meio de entrevistas semiestruturadas. Foram realizadas visitas ao chão de fábrica, permitindo que as impressões e observações do pesquisador fossem consideradas.

A pesquisa foi realizada no período de 01 de setembro a 17 de outubro de 2014. Os entrevistados foram: a equipe Kaizen (responsáveis pela manutenção da filosofia da Produção Enxuta na organização em estudo), operadores de dois setores produtivos da empresa, equipes de manutenção, logística e da engenharia de produção. Assim, busca-se identificar os procedimentos e os principais passos, que a organização participante deste estudo de caso adota, para que os operadores e os colaboradores das áreas de apoio, possam seguir para desenvolver e viabilizar as melhorias desejadas.

A empresa PiraMetals busca a maximização da produtividade e a eficácia das suas operações com base na redução dos desperdícios na produção de componentes e conjuntos soldados em chapas grossas de aço carbono de acordo com as especificações dos clientes. Ela conta com duas unidades de produção, a primeira unidade é responsável pelo corte das peças, e a segunda pelas operações 
agregadas de maior valor como dobra, solda, usinagem e pintura. Todas as operações estão em área coberta, do estoque de matéria prima à expedição. Os subconjuntos (contrapesos e caçambas) apresentados pela Figura 4, são expedidos por meio de embalagens permanentes, garantindo a qualidade do produto até o cliente (montadora).

Figura 4 - Contrapeso e Caçamba
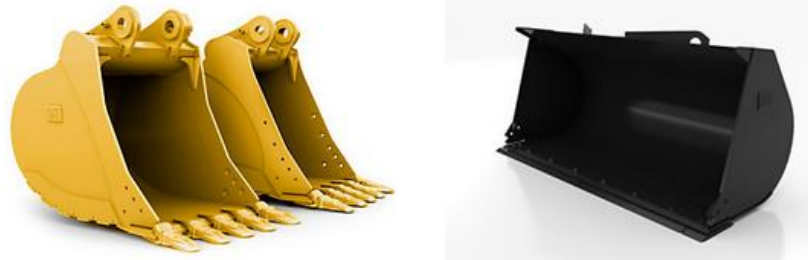

Fonte: Caterpillar (2014)

Estas duas linhas foram escolhidas porque haviam oportunidades de desenvolvimento e melhoria. Elas trabalham com os fluxos empurrados e objetivouse a alteração para fluxos puxados conforme a demanda do cliente.

\section{APRESENTAÇÃO E ANÁLISE dOS RESULTADOS}

Uma série de iniciativas enxutas passíveis de serem adotadas pelas empresas de manufatura, foi encontrada na revisão teórica. Essas iniciativas (ferramentas enxutas) estão supostamente ordenadas e sequenciadas e subentende-se que em forma de passos a serem perseguidos para aplicação e busca da melhoria dos processos produtivos, embora não esteja explicitamente declarada suas sequências e passos de aplicação. Essas organizações contam com alguma cultura da filosofia do Sistema Toyota de Produção (STP) e, minimamente, encontrou-se entre 12 a 19 passos para implementação e viabilização da melhoria, sendo que em um dos casos, adiciona-se um modelo integrado a simulação computacional.

Indo para o chão de fábrica da indústria foco desta pesquisa, inicialmente, realizou-se o primeiro passo para o desenvolvimento de melhorias no processo produtivo, o Pré-Kaizen, e buscou-se por meio do levantamento de dados, a aplicação Mapeamento do Fluxo de Valor atual (MFV - atual) de ambas as linhas, a linha do contrapeso e a linha da caçamba traseira. Esses dois subconjuntos são fabricados em seções diferentes, ou seja, ocupam espaços físicos distintos na fábrica (dois departamentos). 
A duração do Pré-Kaizen foi de dois meses e nessa fase, o trabalho foi orientado pela metodologia DMAIC, uma ferramenta da metodologia Six Sigma que direcionou as atividades, portanto, inicialmente, "D" Definiu-se os objetivos de Kaizen que seria a busca da melhoria do setor e "M" Mediu-se a situação atual identificada no mapa de fluxo de valor atual das linhas e, na sequência, "A" Analisouse a demanda, o balanceamento estimado das linhas e a mão de obra necessária para as operações.

No MFV atual das linhas, por meio da identificação das atividades que agregam valor (AV) e as que não agregam valor (NAV), percebeu-se algumas oportunidades de melhorias. Essas oportunidades identificadas nessa etapa são: (i) Limpeza geral e implementação da gestão visual, (ii) minimização da movimentação das peças, (iii) aproveitamento dos carrinhos para transporte de subconjuntos que estão desativados em outra seção e que poderão minimizar os trabalhos de ponte rolante na área em estudo, (iv) a disponibilização de kits de abastecimentos a serem utilizados pela logística e, (v) implementação de dispositivos facilitadores de montagem dos subconjuntos. Notou-se que a produção estava empurrada. Assim, ficou apontado e definido os próximos, poucos, e vitais passos a serem perseguidos.

Finalmente, partiu-se para a quinta e penúltima letra da sigla do DMAIC, "I" de Implementar, e a execução realizada pelos próprios operadores do setor (equipe kaizen) começou pela base do Kaizen, o 5S. Assim, iniciou-se o segundo passo, desenvolveu-se o layout por meio da aplicação do 5S. A Figura 5 ilustra o antes e o depois das operações de remoção das ferramentas e materiais desnecessários, da organização, limpeza e padronização do setor.

Figura 5 - llustração do antes e depois das melhorias de 5S

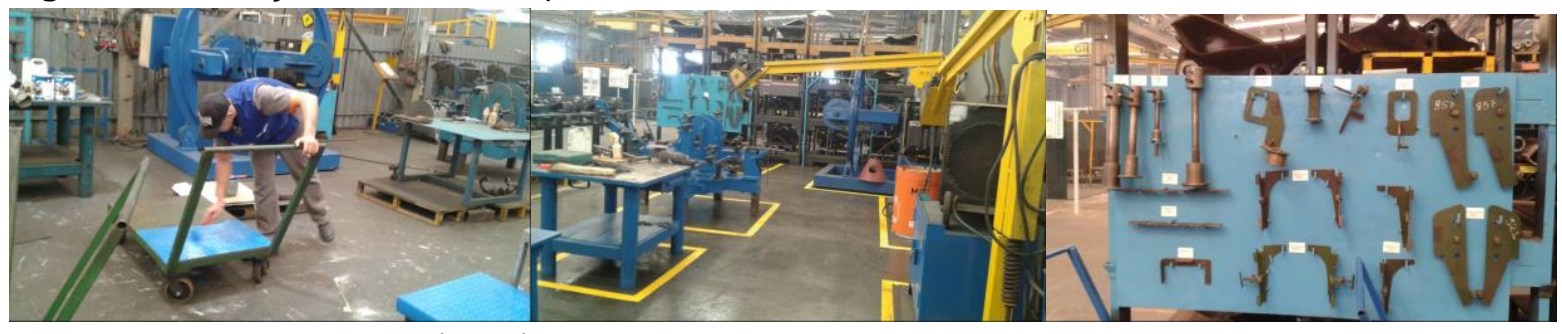

Fonte: Acervo dos autores (2014)

As pinturas no chão demarcaram o posicionamento das bancadas, carrinhos, kits de abastecimentos para estoque de entrada de matéria prima na seção, e espaço para ferramentas. Essas ferramentas foram organizadas e identificadas e o 
estoque de matéria prima, alocado próximo às atividades, reduziu a movimentação e melhorou a produtividade. Assim, eliminaram-se os desperdícios de tempo pela procura de determinada ferramenta e não a encontrar com facilidade.

Implementou-se a gestão visual, como o terceiro passo, a qual orientou os operadores quanto aos procedimentos de sequência das operações, fluxo dos subconjuntos, tempo de cada operação, tempo de ciclo e passou-se a saber quantos subconjuntos (caçambas e contrapesos) devem ser fabricados diariamente.

A Figura 6 apresenta o quarto passo, trata-se de kits de abastecimento projetados pela área de Engenharia de Produção da empresa, para estocar por um dia, a matéria prima que será usada na montagem dos subconjuntos. Esses kits são utilizados pela logística e funcionam como um kanban de abastecimento para o setor. Assim, o sistema produtivo passou de empurrado para puxado.

Figura 6 - Kits de abastecimento projetado e construído (real) para disposição da matéria prima no setor

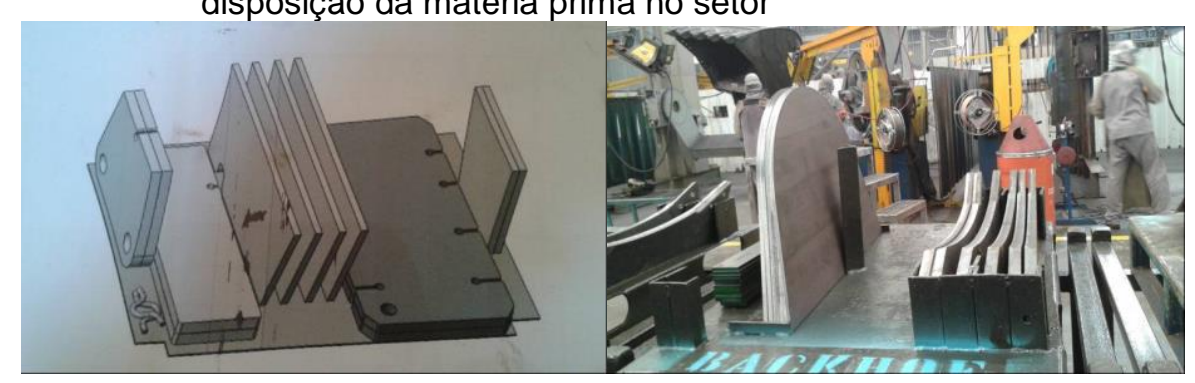

Fonte: Acervo dos autores (2014)

Além dos ganhos de espaço físico e da organização dos materiais e de tempo de movimentação, houve melhorias na qualidade de trabalho para os operadores, pois esses kits de abastecimento foram projetados na altura adequada visando à ergonomia e a facilidade da operação para o trabalhador. Os kits eliminaram a movimentação da matéria prima feita pela ponte rolante com capacidade de cinco toneladas, que raramente estava disponível para utilização dos operadores, e que era o gargalo do setor, pois normalmente os operadores ficavam parados esperando sua disponibilidade.

O quinto passo está na iniciativa da adoção de "carrinhos de mão", também contribuiu para a substituição daquela ponte rolante com capacidade de cinco toneladas, pois os próprios operadores passaram a levar os subconjuntos (Contrapeso e Caçambas) para serem soldados no robô. 
Anteriormente, o robô não participava da atividade de solda nessas duas linhas. Esta foi outra melhoria, pois se aumentou a carga de trabalhos do robô que tinha disponibilidade ociosa, e minimizou a mão de obra dos operadores.

No sexto passo, após a aplicação do kaizen, adotou-se a padronização estabelecida como regra necessária a ser cumprida e mantida. Momento em que se pesquisou junto aos participantes, entre tantas atividades realizadas, compromissos assumidos e várias metas de melhorias: qual seria para eles o maior desafio? A resposta foi unânime. O maior desafio é última letra "C" do DMAIC, o Controle que se trata do acompanhamento e manutenção do que se realizou nesse período de dois meses, ou seja, a manutenabilidade da padronização adotada. Perguntou-se, ainda, aos líderes da equipe kaizen, sobre o fato de não ter utilizado de nenhum modelo de simulação computacional. A resposta foi que em razão da experiência adquirida pelas equipes no passado em vista dos mais de 500 kaizen's realizados, percebeu-se que esse tipo de atividade é mais "mão na massa" e menos computador e escritório (cultura de chão de fábrica). Ainda no passo de planejamento (pré-kaizen), suficientemente para o direcionamento assertivo dos trabalhos, o foco deve estar no realizar/executar, e fazer as coisas realmente na confiança da experiência adquirida pelas equipes. Assim as "coisas" tem se saído melhores.

Em síntese e de forma geral, após seis meses da implementação, alguns resultados quantitativos, apresentados pelo Quadro 1, puderam ser apurados em comparação aos resultados históricos do setor.

Quadro 1 - Resultados apurados na pesquisa com base na produtividade do setor

\begin{tabular}{|l|l|}
\hline Desperdício encontrado e trabalhado & $\begin{array}{c}\text { Dados referente a melhoria do } \\
\text { processo apontados pela pesquisa } \\
\text { após a implementação do kaizen }\end{array}$ \\
\hline (i) Superprodução & Redução do estoque em processo em $55 \%$ \\
\hline (ii) Tempo de espera & Ampliação da capacidade produtiva em $20 \%$ \\
\hline (iii) Transporte desnecessário de peças & Ampliação da capacidade em $35 \%$ \\
\hline (iv) Movimentação desnecessária & Ampliação da capacidade em $50 \%$ \\
\hline
\end{tabular}

Assim, os ganhos foram além do treinamento do pessoal in locu diariamente realizado pela equipe kaizen aos operadores, pois reduziram-se perdas importantes no processo de produção, de forma maximizar a capacidade produtiva. Houve ganhos de $20 \%$ da mão de obra disponível nos setores por não se ter mais o tempo 
de espera que se tinha antes da aplicação do kaizen, sendo esta uma das mais danosas em razão da quantidade de colaboradores.

Os desperdícios de (i) superprodução, (ii) tempo de espera, (iii) transporte desnecessário de peças e, (iv) movimentação desnecessária, tem a propriedade de esconder as outras perdas e são as mais difíceis de serem eliminadas. Deixou-se de produzir demais (superprodução por quantidade) e não se produz mais antecipadamente (superprodução por antecipação). Reduziu-se o desperdício com a superprodução, tempo de espera, transporte desnecessário e movimentação excessiva de peças em 55\%, 20\%, 35\% e 50\%, respectivamente. Nesse cálculo, foram considerados o intervalo de tempo no qual o lote ficava "estacionado" à espera de sinal verde para seguir em frente no fluxo de produção, e o tempo de movimentação e transporte economizados no fluxo de peças e componentes.

Por meio dos kits de abastecimento próximos as operações de montagem dos componentes foram economizadas $45 \%$ do tempo de processamento. Eliminaram-se tarefas sem afetar as características e funções básicas do produto/serviço. Estas foram classificadas como perdas no próprio processamento, são situações em que o desempenho do processo encontra-se aquém da condição ideal. Exemplos das melhorias conquistadas: (i) aumento na velocidade de corte, (ii) montagem, (iii) solda e eliminou-se a necessidade de (iv) ajuste das máquinas. Portanto, em razão dos kit's e pelo rearranjo do layout, foi possível mensurar ganhos de produtividade.

Após a implementação desses seis passos, a empresa incorporou a importância da aplicação do kaizen, e decidiu seguir com o processo em outras áreas da organização na tentativa de conquistar ganhos macros pela redução do tempo global de produção e de seus benefícios inerentes as melhorias percebidas.

\section{CONSIDERAÇÕES}

Com poucos e a identificação dos mais importantes passos para implementação de kaizen evidenciados nessa pesquisa, e por meio uma sequência lógica, prática, objetiva e que se notou ser bem-sucedida, realizou-se intervenções e se promoveu melhorias no processo produtivo de uma indústria do segmento metal mecânico localizada no interior do estado de São Paulo.

Face ao que foi desenvolvido na prática dessa indústria pelo seguimento desses seis passos, e com o apoio do que se encontrou na revisão da literatura da 
área da Engenharia de Produção, foi possível viabilizar um processo produtivo mais enxuto em razão da eliminação dos desperdícios encontrados.

Os seis passos escolhidos e seguidos tornaram o trabalho objetivo, simples, focado e de fácil assimilação pelos operadores. O DMAIC foi a ferramenta utilizada para direcionar e nortear as atividades que, por ser um ciclo, pode possibilitar depois de implementado as melhorias identificadas, reiniciar o estudo, ciclicamente. $E$, assim, executar outras novas possibilidades de melhorias, ininterruptamente, melhorando o processo produtivo.

O primeiro passo consiste no pré-kaizen, e na identificação e levantamento de dados o Mapeamento do Fluxo de Valor atual (MFV). O segundo passo está no desenvolvimento do layout por meio da aplicação do 5S. A implementação da gestão visual, como o terceiro passo, orientou os operadores quanto aos procedimentos eficientes das operações para viabilizar resultados eficazes de fabricação. O quarto passo, trata-se de kits de abastecimento projetados, momento em que o sistema produtivo passou de empurrado para puxado, esse sistema possibilitou puxar a produção conforme a demanda e, por meio do balanceamento da linha o estoque de matéria prima na seção foi minimizado. O quinto passo está na iniciativa da adoção de "carrinhos de mão" oportunidade em que se reduziu o tempo de movimentação e de espera. No sexto passo, após a aplicação do kaizen, adotou-se a padronização estabelecida como regra necessária a ser cumprida e mantida.

Assim, foi possível reduzir desperdícios de (i) superprodução, (ii) tempo de espera, (iii) transporte desnecessário de peças e, (iv) movimentação desnecessária, para ambas as linhas. As linhas de contrapeso e de caçambas traseiras transformaram-se uma única linha, ganhou-se metros quadrados de área de fábrica ocupada e a redução de cinco colaboradores que foram alocados em outras atividades encomendadas por um novo cliente da empresa.

De ambas as linhas, a linha escolhida para produzir o contrapeso e as caçambas traseiras foi a mais próxima do robô o que diminuiu ainda mais a movimentação de subconjuntos pela fábrica. Consequentemente, reduziu-se a utilização da ponte rolante (que possui capacidade de cinco toneladas), isso porque os próprios operadores, por meio de carrinhos que foram reaproveitados de outros setores que os haviam desativados, passaram a levar os subconjuntos para solda no robô. 
Uma vez identificado os seis passos realizados pela empresa e implementado as melhorias no processo produtivo, mensurou-se os ganhos quantitativos e as áreas na qual foram aplicadas o kaizen. Além dos ganhos de espaço físico, organização dos materiais e de tempo de movimentação, houve melhoria na qualidade de trabalho para dos operadores. Portanto, os ganhos foram além do aumento da capacidade produtiva e treinamento e capacitação do pessoal.

Os seis passos possibilitaram a redução de perdas importantes no processo de produção, houve ganhos de $20 \%$ da mão de obra disponível. Minimizou-se o desperdício com o tempo de espera, movimentação adicional e transporte excessivo de peças. $O$ abastecimento de componentes próximos às operações de montagem resultou em ganho de $45 \%$ do tempo de processamento.

Essas melhorias serão revertidas em garantia de entrega no prazo, melhoria de qualidade dos subconjuntos e maior confiança na relação entre fornecedor e clientes. E, espera-se uma maior credibilidade por parte da montadora, o que poderá ser um diferencial para torná-lo mais competitivo frente aos concorrentes, e assim maximizar as vendas de seus produtos.

Observando a situação inicial da empresa, e aderindo a iniciativa dos seis passos adotados prioritariamente, e por meio de uma sequência lógica, prática, simples e objetiva, conquistou-se os resultados esperados. Adiciona-se, ainda, a esses resultados quantitativos, as mudanças no método de trabalho e na satisfação do pessoal, operadores e colaboradores mais motivados e com autoestima elevada, pela satisfação do trabalho realizado bem-sucedido. Além do ambiente mais agradável de trabalho, pôde-se mensurar melhores resultados conquistados pela equipe (redução do tempo de ciclo, entre outros).

O objetivo principal deste trabalho foi identificar uma quantidade de passos mínimos (seis passos) praticados pela indústria na implementação de kaizen's. $\mathrm{Na}$ qual é possível aplicar os conceitos da Engenharia de Produção no processo produtivo, eliminar desperdícios de um fabricante de equipamentos seriados e identificar seus benefícios. Com isso, sugere-se que esta empresa, e outras, estenda a aplicação desses passos de forma focada e objetiva para outras linhas de produtos e para outros setores da empresa, como o setor administrativo e almoxarifado. 


\section{REFERÊNCIAS}

BERTHOLEY, F. BOURNIQUEL, P. RIVERY, E. COUDURIER, N. \& FOLLEA, G. Work organization improvement methods applied to Blood Transfusion Establishments (BTE): Lean Manufacturing, VSM, 5S. Transfusion Clinique et Biologique, v.16, n.2, p. 93-100. 2009. https://doi.org/10.1016/i.tracli.2009.04.007

CATERPILLAR. Disponível em: <http://www.cat.com/pt BR.html> . Acesso em : 24 out. 2014.

CELIS, O. L. M.; GARCÍA, J. M. S. Modelo tecnológico para el desarrollo de proyectos logísticos usando Lean Six Sigma. Estudios Gerenciales, v. 28, 2012.

DÜES, C. M.; TAN, K. H.; LIM, M. Green as the new Lean: how to use Lean practices as a catalyst to greening your supply chain. Journal of cleaner production, v. 40, p. 93-100, 2013. https://doi.org/10.1016/j.jclepro.2011.12.023

FAVONI, C., GAMBI, L. N., CARETA, C. B. Oportunidades de implementação de conceitos e ferramentas de produção enxuta visando melhoria da competitividade de empresas do APL calçadista de JAÚ/SP. Revista Produção Online, Florianópolis, SC, v.13, n. 3, p. 11181142, jul./set. 2013. http://dx.doi.org/10.14488/1676-1901.v13i3.1404

GAPP, R.; FISHER, R.; KOBAYASHI, K. Implementing 5S within a Japanese context: an integrated management system. Management Decision, v. 46, n. 4, p. 565-579, 2008. https://doi.org/10.1108/00251740810865067

GSTETTNER, S., e KHUN, H.: Analysis of production controlsystems Kanban and CONWIP.International. Journal of Production Research, v.34, p. 3253-3273, 1996. http://dx.doi.org/10.1080/00207549608905087

HOMINISS. Empresa de consultoria e treinamento. Disponível em: <http://www.hominiss.com.br/>. Acesso em: 04 jan. 2015.

HOPP, W. J.; SPEARMAN, M. L. A Ciência da fábrica. 3.ed. 2013.

IMAI, M. Kaizen: a chave para o sucesso competitivo do Japão. Random House Negócios Division, New York, NY, 1986.

JOHANSSON, P. E. C. LEZAMA, T. MALMSKÖLD, L. SJÖGREN, B. AHLSTRÖM L. M. Current State of Standardized Work in Automotive Industry in Sweden. Procedia CIRP. Vol 7, p.151-156. 2013.https://doi.org/10.1016/j.procir.2013.05.026

KASAHARA, E. S.; CARVALHO, M. M. Análise dos Modelos TQM e Seis Sigma: estudo de múltiplos casos. In: ENEGEP - ENCONTRO NACIONAL DE ENGENHARIA DE PRODUÇÃO, 23., 2003. Anais... Ouro Preto. Porto Alegre: UFRGS, 2003. p. 1-8.

LEXICO LEAN - Glossário ilustrado para praticantes do pensamento lean. 4. ed. Lean Enterprise Insitute. 2003.

LIKER, J. K. The Toyota way: 14 management principles from the world's greatest manufacturer: MacGraw-Hill, 2004.

MANO, Y., AKOTEN, J., YOSHINO, Y., SONOBE, T., Teaching KAIZEN to small business owners: An experiment in a metalworking cluster in Nairobi. Journal of the Japanese and 
International Economies, v. 33, p. 25-42, set. 2014. https://doi.org/10.1016/j.jiie.2013.10.008

MARKSBERRY, P., BADURDEEN, F., GREGORY, B., KREAFLE, K., Management directed kaizen: Toyota's Jishuken process for management development. Journal of Manufacturing Technology Management, v. 21, n. 6, 2010. https://doi.org/10.1108/17410381011063987

MIGUEL, P. A. C., Estudo de caso na engenharia de produção: Estruturação e recomendações para sua condução. Produção, v. 17, n. 1, p. 216-229, Jan./Abr. 2007. http://dx.doi.org/10.1590/S0103-65132007000100015

OHNO, T. O Sistema Toyota de produção: além da produção em larga escala. Porto Alegre: Bookman, 1997.

OLIVEIRA, R. B. M., CORRÊA, V. A., NUNES, L. E. N. P. Mapeamento do fluxo de valor em um modelo de simulação computacional. Revista Produção Online, Florianópolis, SC, v.14, n. 3, p. 837-861, jul./set. 2014. http://dx.doi.org/10.14488/1676-1901.v14i3.1461

ROTHER, M. Learning to see: value stream mapping to add value and eliminate. Lean Enterprise Institute; 2003.

SCHELLER, A. C., MIGUEL, P. A. C. Adoção do seis sigma e lean production em uma empresa de manufatura. Revista Produção Online, Florianópolis, SC, v.14, n. 4, p.13161347, out./dez. 2014. http://dx.doi.org/10.14488/1676-1901.v14i4.1652

SEELING, M., PANITZ, C. Estudo de layout. Transparências. 1997.

SINGH, J.; SINGH, H. Kaizen philosophy: a review of literature. The IUP Journal of Operations Management, v. 8, n. 2, p. 51-72, 2009.

SINGHA, R. GOHILB, A.M. SHAHB, B.D. DESAIC, S. Total Productive Maintenance (TPM) Implementation in a Machine Shop: A Case Study. Procedia Engineering, v. 51, p. 592599, 2013. https://doi.org/10.1016/j.proeng.2013.01.084

SPEARMAN, M. L.; WOODRUFF, D. L.; HOPP, W. J.: CONWIP: a pull alternative to Kanban. International Journal of Production Research. v. 28, n.5, p. 879-894, 1990.

SUÁREZ-BARRAZA, M. F.; RAMIS-PUJOL, J.; KERBACHE, L.. Thoughts on < IT> kaizen $</ I T>$ and its evolution: Three different perspectives and guiding principles.

International Journal of Lean Six Sigma, v. 2, n. 4, p. 288-308, 2011. https://doi.org/10.1108/20401461111189407

THOMAS, K.P. Investment incentives and the global competition for capital. Journal of common market studies, v. 50, n. 1, 2012. DOI: 10.1111/j.1468-5965.2011.02215 5.x

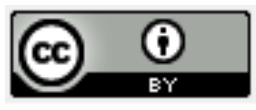

Artigo recebido em 29/06/2016 e aceito para publicação em 17/10/2017 DOI: http://dx.doi.org/10.14488/1676-1901.v17i4.2512 